\title{
Automotive Electronic Control Parking Based on CAN Communication
}

\author{
Bingzhao Xu, Qinglie Su, Ronggui Zhang \\ Department of Automotive Application Engineering, Fujian Chuanzheng Communications College, Fuzhou, China
}

\section{Email address:}

shmmd@126.com (Bingzhao Xu)

\section{To cite this article:}

Bingzhao Xu, Qinglie Su, Ronggui Zhang. Automotive Electronic Control Parking Based on CAN Communication. Engineering and Applied Sciences. Vol. 3, No. 2, 2018, pp. 47-52. doi: 10.11648/j.eas.20180302.12

Received: May 31, 2018; Accepted: June 12, 2018; Published: July 7, 2018

\begin{abstract}
Based on CAN (Controller Area Network) communication safe strategy for automotive parking, we first analyze the structure and operation principle of the typical disc electronic control parking brake, and then intensive study its dynamic executive mechanism. With an example of ESP parking brake force calculation, a safe strategy scheme of parking brake and vehicle matching is proposed.
\end{abstract}

Keywords: Automobile, CAN Communication, Electronic Parking, Control Technique

\section{Introduction}

Electrical Controlled Park Brake (ECPB) uses the power of motor to implement or remove parking brake. It integrates the temporary braking in the course of driving with the long-time braking function after stopping, and implements parking brake, emergency braking (dynamic braking), automatic brake application after engine shut - off, automatic brake release (off), and monitoring of vehicle movement during parking [1-2]. With the electronic control system, it is easy to start on the ramp and adjust the braking clearance, which improves the safety and reliability of the vehicle [3-5]. In 2001, The electrically controlled parking technology was first applied in Fiat Lancia. Subsequently, Joint venture between China and foreign countries, including European, American and Japanese enterprises of mid-high grade cars have been used to varying degrees. This is the inevitable trend of the application and development of vehicle parking technology [6].

\section{The Type of ECPB}

At present, the electrically controlled parking brake system can be divided into two types: cable traction type and integrated caliper type [6-7].

\subsection{The Cable Traction Electrically Controlled Parking Brake System}

The cable traction type electric control parking actuator is the same as the traditional hand brake. It appears as a brake shoe (or brake disc) type. It uses the electronic control module instead of the hand brake cable balancer to balance the brake force on the left and right side of the car., as shown in figure 1. Because of the low installation cost and compact structure of the cable traction electronic control parking device, it is more favorable for the design change of the ordinary type of vehicle when it is applied.

\subsection{The Integrated Calliper Electrically Controlled Parking Brake System}

The integrated caliper electronically controlled parking brake system requires special brake calipers and related actuators, all of which are located on the rear wheel brake calipers, without the traditional handbrake cables, and the system becomes simpler, as shown in figure $2 \mathrm{~b}$. But the cost is relatively high. Since the integrated electrically controlled parking brake system of caliper type adopts electric wire to transmit the command signal, it is more convenient for the assembly of ordinary vehicles and the simplification of the parking system or refit, and it is more economical and practical. 


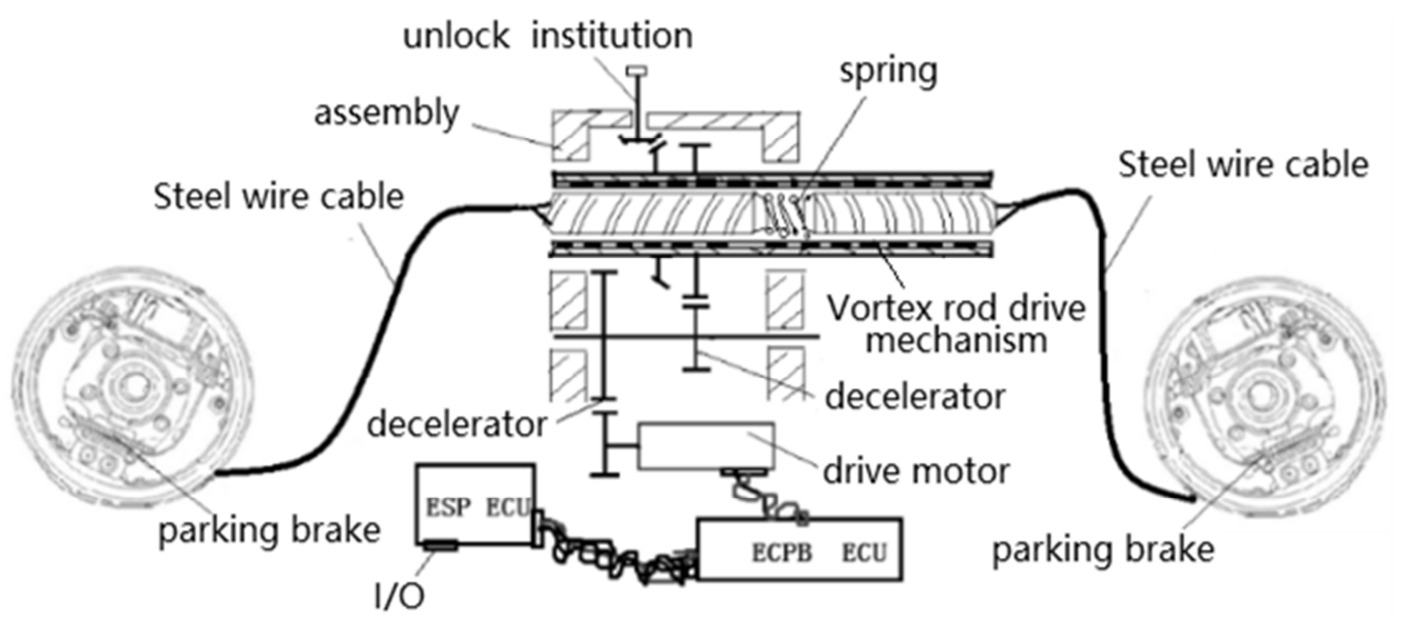

Figure 1. The schematic diagram of steel cable traction electric control parking brake system.

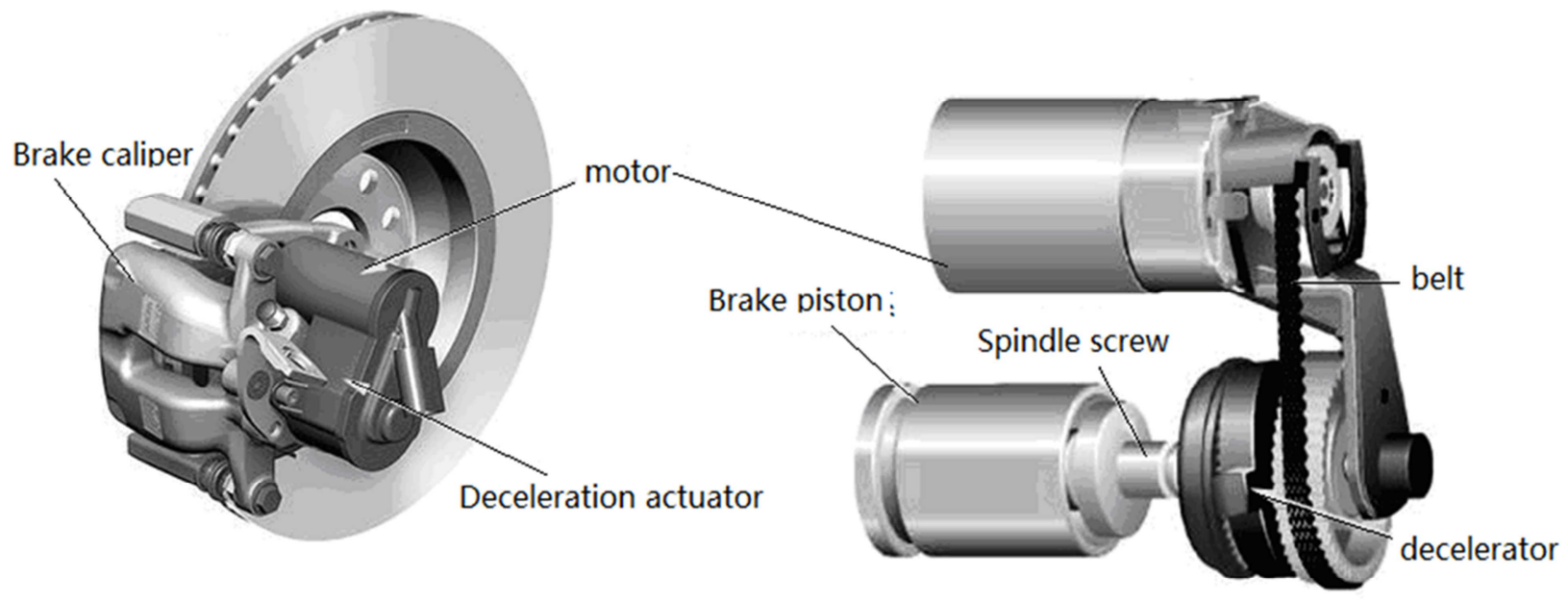

a) integrated caliper electrically controlled parking brake system;

b) actuator

Figure 2. The Schematic diagram of integrated caliper type electrically controlled parking brake mechanism.

\section{The Structure Composition and Principle of ECPB}

\subsection{ECPB Structure Composition}

The hardware of the control system is mainly composed of three parts: sensor, signal communication and processing circuit, electronic control module, actuator and driving circuit, and its block diagram is shown in figure 3. The ECPB module is controlled by ESP (Electronic Stability Program).

The controller collects speed, engine speed, parking brake switch (note: mechanical type is hand brake), clutch position, gear-box position, brake pedal switch, road slope signal, acceleration pedal position, brake force sensor, etc. and the control command is output to the left and right brake forceps parking actuator. The network structure in car is composed of CAN power IS network, CAN body network and CAN comfort network, etc..

\subsubsection{The Communication Between ESP Module and Parking Control Module}

The information received by the electronic parking brake control module [8] is as follows:

1) If the brake must be sustained, released or made independent, the ESP control module shall issue instructions to the electrically controlled parking brake.

2) The braking and release settings calculated by the ESP control module can be based on the vehicle's slope, weight, shutdown engine requests, and when pressing the electronic parking brake control key, the torque and accelerator pedal will enhance or weaken the braking force or release brake.

3) The speed at which the motor rotates depends on the power supply voltage diagnosed according to the ESP control module, and the parking brakes are used at different speeds (if the battery voltage is lower, the application speed is slower). 


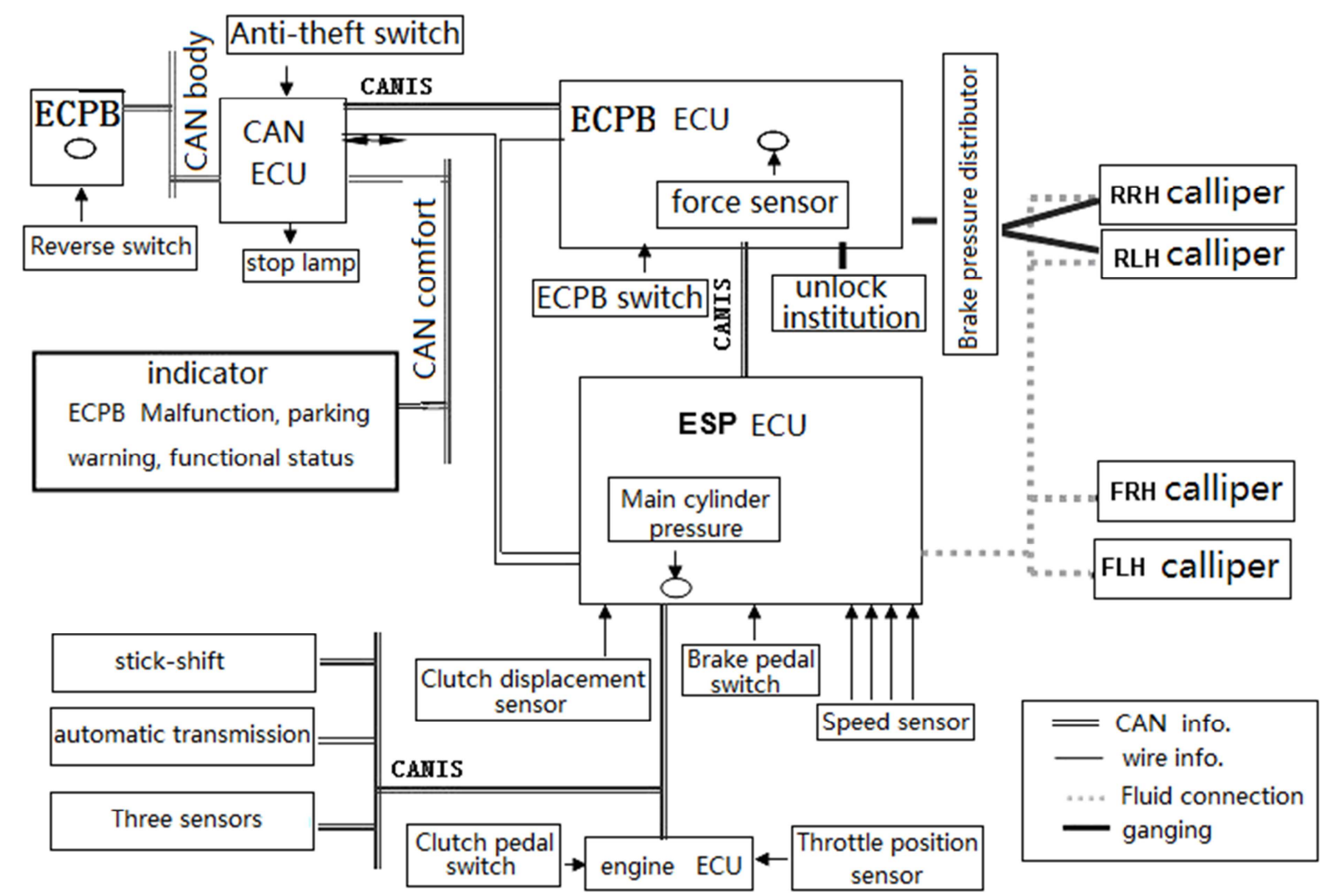

Figure 3. The schematic diagram of ECPB system structure.

\subsubsection{The Communication Between Parking Control Module and ESP Control Module}

The communication between the electronic control brake module and the ESP control module $[8,9]$ is as follows:

1) The brake force applied to a brake (or cable);

2) The state display of Electric Control device of parking Brake;

3) The real-time State of automatic function of parking Brake;

4) The fault Self-diagnosis of parking Brake.

The actuators of ECPB are mainly composed of DC motor, transmission belt, planetary gear reducer, worm drive mechanism, brake disc and brake friction plate, etc., as shown in figure 4.

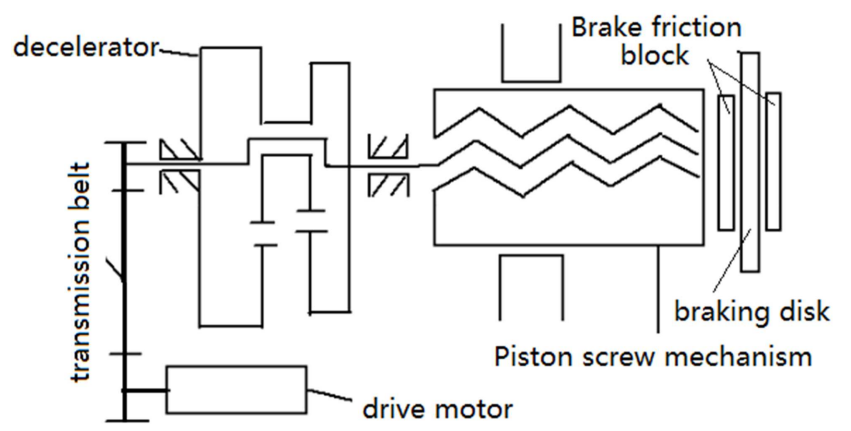

Figure 4. The composition of executive body, schematic diagram of principle.

\subsection{The Working Principle of ECPB Actuator}

When the ECPB is working, the ESP control module sends the parking instruction to the parking control module. After the motor output increases and the torque is increased by the speed reduction of the drive belt and the planetary gear reducer, the rotating motion is transformed by the worm drive mechanism into the linear motion of the brake wheel cylinder piston. Finally, the brake force is produced by brake friction disc.

When the parking brake needs to be released, the motor reverses and the brake friction plate is released.

Because of the large transmission ratio of the planetary gear reducer and the small linear displacement of the piston of the brake wheel cylinder driven by the worm drive mechanism, the clearance between the brake disc and the brake friction disc can be controlled by controlling the speed of the motor, and the function of automatic adjustment of brake clearance can be obtained.

\subsection{The Braking Strategy of ECPB [9-10]}

\subsubsection{The Braking Parking Strategy Based on ESP}

The ESP control module determines the brake based on the "engine state", "vehicle speed", "automatic function status" information, and related delay time (no restart in a short time). The ESP computer issues an application electrically controlled parking brake instruction under the following conditions:

1) When the ESP control module detects the vehicle 
movement and applies the electrically controlled parking brake at the same time, the ESP will request the maximum application braking force (with emergency braking).

2) If the braking force conforms to the strategy 1 of Table 1 , then the engine becomes "engine not running" state, and the function of "electrically controlled parking brake" is in automatic mode. If the difference between the applied braking force and the reference braking force is greater than $7 \%$, the ESP control module emits a braking force application that conforms to Table 1's Strategy 2.

3) If the braking force applied conforms to Table 1's strategy 1 , and the monitoring time is longer than 10 minutes, and the difference between the applied braking force and the reference braking force is more than $3 \%$, then the ESP control module emits a brake force that conforms to the strategy 2 of
Table 1.

4) If no trouble is detected, the ESP control module emits the maximum speed of the rotating setting of the electrically controlled parking brake motor.

5) If the braking force applied is in line with table 1, the ESP control module should not be released or reapplied when the slope changes.

During the automatic application of the engine whit sudden flameout, the parking control module will use the braking force issued by the ESP control module.

When the engine is closed and the parking brake is determined, the ESP control module sends the application reference value to the electrically controlled parking brake in accordance with the strategy 2 of Table 1 .

Table 1. The description of parking Strategy conditions for Electronic control brake.

\begin{tabular}{ll}
\hline Strategy condition & The implementation condition of electrically controlled parking brake \\
\hline $\begin{array}{l}\text { Strategy } 1 \\
\text { if }\end{array}$ & $\begin{array}{l}\text { Parking is determined } \\
\text { The function of "electrically controlled parking brake" is in automatic mode } \\
\text { and } \\
\text { and }\end{array}$ \\
and & The below $6 \%$ \\
Then & Under the maximum speed of the electronic parking brake motor, the ESP ECU will send an application reference value of $76 \%$ \\
braking force. & \\
if & Parking is determined \\
and & The function of "electrically controlled parking brake" is in automatic mode \\
and & Slope below $6 \%$ \\
and & The braking force of the electrically controlled parking brake in $+3 \%$ application is lower than $100 \%$ of the applied reference value. \\
then & Under the maximum speed of the electronic parking brake motor, the ESP ECU will send an application reference value of $100 \%$ \\
\end{tabular}

\subsubsection{The Strategy of Requesting the Release of Electrically Controlled Parking Braking at Start}

When the driver requests the starting information to be confirmed, the electrically controlled parking brake will release the braking force on the rear brake caliper and strategy conditions are shown in Table 2.

Table 2. The release of electrically controlled parking brake conditions.

\begin{tabular}{ll}
\hline Strategy condition & Requirements for release of electrically controlled parking braking conditions \\
\hline if & The driver's request has been confirmed. \\
and & Parking brake controller released \\
and & The function of "electrically controlled parking brake" is in automatic mode \\
and & Applied, ready to be applied or released from parking \\
then & When the motor speed of electrically controlled parking brake is maximum, the ESP ECU sends the release order \\
\hline
\end{tabular}

\subsubsection{The Braking Force Strategy for Monitoring and Maintaining ESP Requirements During Parking}

During parking monitoring, the brake control module measurement will be applied to braking force of brake forceps, and its error is $\pm 10 \%$. If the braking force is lowered, the electric control parking brake control module will apply additional braking force to the brake caliper to meet the effect of reference values of the ESP requirements. Once the brake pedal is operated or a specific mechanism is implemented, the electronic parking brake control module will immediately notify the vehicle to monitor the situation of the grabbing. When the braking force applied to the brake forceps is lower than the brake force that produces the initial braking function, the reduction of braking force applied to the brake forceps will be detected. At this time, if the electrically controlled parking brake does not meet the brake requirements, the parking system will restore the reference values required by the ESP control module.

\section{The Dynamic Characteristic Analysis of Integrated Calliper ECPB}

\subsection{The Determination of Maximum Braking Torque [11-12, 14]}

Suppose the vehicle needs to be parked on the slope road at angle a, half of the maximum torque of ECPB's single rear wheel parking braking torque is: 


$$
\mathrm{T}_{\max }=\frac{1}{2} G R_{e} \sin \alpha_{\max }
$$

Type center:

$\mathrm{G}$ - whole vehicle quality;

$\mathrm{R}_{\mathrm{e}}$ - rear wheel effective rolling radius;

$\mathrm{a}_{\max }-$ maximum slope angle.

\subsection{The Analysis of Braking Torque Transmission Characteristics of Brake [13]}

In addition to the minimum configuration of vehicles, The rear wheel of medium and advanced vehicles is installed disc brake (here's an example of a disc brake), its braking torque is:

$$
\begin{aligned}
& \mathrm{T}_{0}=2 \mu \mathrm{FR} \\
& \mathrm{R}=\frac{2\left(R_{2}^{3}-R_{1}^{3}\right)}{3\left(R_{2}{ }^{2}-R_{1}^{2}\right)}
\end{aligned}
$$

Type center:

$\mu$-friction factor;

$\mathrm{R}$-braking force radius;

$\mathrm{F}$-braking force of brake friction block on brake disc;

$\mathrm{R}_{1}, \mathrm{R}_{2}$ - the internal radius and outer radius of the brake friction block on the brake disc.

\subsection{The Calculation of Maximum Compression Force of Brake [11-13]}

If a safe and reliable parking is required, the braking torque should be met the conditions:

$$
\mathrm{T}_{0}=\gamma \mathrm{T}_{\max }
$$

Type center: $\gamma$-safety factor, its value is calculated according to the test, and its value is more than 1 .

According to type (1) and type (2), we can get:

$$
2 \mu \mathrm{F}_{\max } \mathrm{R}=\frac{1}{2} \gamma G R_{e} \sin \alpha_{\max }
$$

go a step further: $\mathrm{F}_{\max }=\gamma \mathrm{GR}_{\mathrm{e}} \sin \alpha_{\max } /(4 \mu \mathrm{R})$

Type center: $\mathrm{F}_{\max }$ - maximum compression force of brake friction block on brake disc.

The output torque of the actuator motor should be slightly larger than the maximum pressure of the brake disc by the maximum brake friction block after the torque is increased by the reducer.

\section{The Checking Calculation of Electronic Control Parking Braking Force Based on ESP}

\subsection{The Test Vehicle Sampling}

According to the existing test conditions, we select a certain European brand car parameters as shown in Table 3 [10]. The car is equipped with automatic auxiliary parking function, and the driver can be set through the central control panel switch, which can be set as automatic parking or manual parking. If the vehicle is parked or starts on the slope, the ESP control module will issue instructions to the parking control module to keep the brake pressure for a while. The driver can release the

\begin{tabular}{|c|c|c|c|}
\hline engine type & EW10A & vehicle type & DC7204LLAA \\
\hline \multirow[b]{2}{*}{ characteristics } & \multirow{2}{*}{$\begin{array}{l}\text { Straight four-cylinder, } 16 \text { valve } \\
\text { with double cam continuous } \\
\text { variable valve }\end{array}$} & complete vehicle kerb mass $(\mathrm{Kg})$ & 1520 \\
\hline & & maximum autohrozed total mass $(\mathrm{Kg})$ & 1985 \\
\hline cylinder volume $\left(\mathrm{cm}^{3}\right)$ & 1997 & maximum speed(km/h) & 198 \\
\hline compression ratio & $11 / 1$ & maximum climb gradient(\%) & 30 \\
\hline maximum power(KW/r/min) & $108 \mathrm{~kW} / 6000 \mathrm{rpm}$ & full load parking slope $\geq(\%)$ & 20 \\
\hline acrot orque $(\mathrm{Nm} / \mathrm{r} / \mathrm{min})$ & $200 \mathrm{~N} \cdot \mathrm{m} / 4000 \mathrm{rpm}$ & rated pressure of tire $(\mathrm{kpa})$ & $\begin{array}{l}\text { no load: front } 200 \text {, rear } 200 \\
\text { full load: front } 300 \text {, rear } 300\end{array}$ \\
\hline electronic management system & MED17.4 & tyre size & 225/50R17V \\
\hline $\begin{array}{l}\text { minimum fuel consumption/ } \\
\text { rotational speed }\end{array}$ & $229 \mathrm{~g} / \mathrm{kw} \cdot \mathrm{h} / 2000 \mathrm{rpm}$ & front brake disc(mm) & $\begin{array}{l}302 \times 26 \text { ventilated disc, sub pump } \\
\text { diameter } 57\end{array}$ \\
\hline idling (rpm) & $720 \pm 50 \mathrm{rpm}$ & rear brake disc $(\mathrm{mm})$ & $268 \times 12$ solid disk, sub pump diameter $\phi 38$ \\
\hline network architecture & CAN2010 & brake main cylinder diameter(mm) & ф23.8 \\
\hline
\end{tabular}
brake pedal during this period of time to accelerate, but the vehicle will not fall back, and the brake pressure will be released automatically after the vehicle starts.

Table 3. The main structural parameters of vehicles to be verified.

\subsection{The Calculation of Maximum Compression Force for Sampled Vehicles}

When the parking control module requests the braking force of ESP to be applied, the sensitivity of measuring brake force applied to brake forceps is $\pm 15 \%$. The calculation results of the discrete points of the sample's maximum compacting force are shown in table 4.

Table 4. The checking calculation of maximum pressing force of brake disc on brake disc.

\begin{tabular}{lllllll}
\hline checking point & F0 & F1 & F2 & F3 & F4 & F5 \\
\hline longitudinal grade & $0 \%$ & $10 \%$ & $10 \%$ & $13 \%$ & $16 \%$ & $17 \%$ \\
braking force checking value & $455 \mathrm{~N}$ & $568 \mathrm{~N}$ & $856 \mathrm{~N}$ & $1023 \mathrm{~N}$ & Higher than $17 \%$ & $1128 \mathrm{~N}$ \\
\hline
\end{tabular}


The sample analysis:

According to the results of discrete sampling test of the maximum compression force of the brake disc by the brake friction block mentioned above, we sort out the data and thus it can be seen: With the increase of slope, the maximum compression force of brake friction block on brake disc is increasing also. When the longitudinal slope is higher than $17 \%$, the value of the vehicle is no longer increased due to the maximum allowable total mass of the vehicle on the ramp. As a result shows that The experimental values are compared with the technical parameters (theoretical values) of the vehicle, there is a difference in the slope $\geq 20 \%$ whit the full load parking. In other words, the maximum slope of the vehicle is $17 \%$ and the error is $-3 \%$.

Therefore, the determination of the maximum braking torque provides reference for motor matching and selection because of the motor as the driving element of the actuator.

It provides the key technical support for the CAN communication of ECPB above the informations.

The reasonable matching of electrically controlled parking brake force required by ESP must fully be met the data requirement of system security strategy to improve safety and reliability.

\section{Conclusion}

The electronic control parking technology based on CAN communication relates to the integrated application of the field of Machine, electricity, hydraulic and vehicle network. The technology is being continuously improved [14, 15]. Therefore, the development of this technology can be carried out in the direction of strengthening the multi-function of integrated body controlling system in future [14]. At the same time, combined with the safety strategy of ESP system, the vehicle stability control and the auxiliary function of driving safety are realized.

1). Controling the parking system through the ESP computer, it is an extension of an active security strategy and depends on the application of three sensors (longitudinal acceleration, lateral acceleration and ramp angle sensor), and it is the key to realize the function of electrically controlled parking.

2). The braking force strategy of automatic monitoring and maintenance required by ESP during the parking period is also an extension of the active security policy. It depends on the sensor application of the force in the electric control parking module, and realizes the real time monitoring information acquisition function of the vehicle grip condition.

3). Based on CAN communication needs, the network structure is relatively complex, and the automatic parking security policy is guaranteed due to rapid communication. It is also the mainstream of parking technology in the future.

\section{Fund Projects}

The Category A Project (JA14373) of the Department of Education of Fujian and the Technology Project (2014Y062) of Department of Communications of Fujian.

\section{References}

[1] Yanfang SONG. Research on development and application of automotive electronic parking braking system (EPB) [J]. Electronic Technology and Software Engineering, 2014(17):265-266.

[2] Jonner W D, Winner H, Dreilich L. Electro-hydraulic brake system-the first approach to brake-by-wire technology [R] SAE, 1996.

[3] Sone S. Ucda N. Improvement of charactcristies by introducing pure electric braking [J]. Proc. IEEJ-IAS, 1997, 303 (3):415-418.

[4] Ralf Leiter. Design and control of an electric park brake [C]. SAE Paper, 2002(01):25-83.

[5] Lei WANG, li YAN, liyuan TIAN. Research and implementation of CAN general route technology in automobile network [J]. Journal of Changchun University of Technology: Natural Science Edition, 2007, 28 (4):402-406.

[6] Juanying ZHOU. Development and application of automotive electronic parking brake system (EPB) $[\mathrm{J}]$. Electronic Test, 2014(04): 17-18.

[7] Dawei JIANG. Research on the application of electronic parking braking system [J]. Journal of Automotive Engineers, 2012(1):60-64.

[8] Soutao LI; yongxue MA ect. Vehicle stability control strategy based on electro-hydraulic braking system [J]. Journal of Jilin University: Engineering Edition, 2015(02):526-529.

[9] Jianting Guo. Design and research on electronic parking brake system for automobile based on CAN bus [C]. Degree Thesis of Changan University, 2014(06):45-63.

[10] SINO automobile training department. DPCA Automobile Co., Ltd. Vehicle Manual [M]. (Publisher Unknown), 2013.

[11] Xianwu GONG; lijun ZHANG ect. Distribution of electronic braking force based on braking stability requirement $[\mathrm{J}]$. Journal of Changan University, 2014(1):103-108.

[12] Zhisheng YU. Automobile Theory [M]. Beijing: Mechanical Industry Press, 2009.

[13] Wangyu WANG. Theory and Design of Automobile Braking [M]. Changchun: Jilin University Press, 2012.

[14] Junjie WU. Research on inclination sensor of electronic parking braking system based on MEMS [J]. Journal of Wuhan University of Technology, 2015(03):277-291.

[15] Chaoyong WANG. Research on hardware design of electronic parking EPB Control system [C]. Nanjing University of Technology, 2009(05): 8-16. 